IZA DP No. 9732

The Prodigal Son: Does the Younger Brother Always Care for His Parents in Old Age?

Mizuki Komura

Hikaru Ogawa

February 2016 


\title{
The Prodigal Son: Does the Younger Brother Always Care for His Parents in Old Age?
}

\author{
Mizuki Komura \\ Nagoya University \\ and IZA \\ Hikaru Ogawa \\ University of Tokyo

\section{Discussion Paper No. 9732 \\ February 2016} \\ IZA \\ P.O. Box 7240 \\ 53072 Bonn \\ Germany \\ Phone: +49-228-3894-0 \\ Fax: +49-228-3894-180 \\ E-mail: iza@iza.org
}

Any opinions expressed here are those of the author(s) and not those of IZA. Research published in this series may include views on policy, but the institute itself takes no institutional policy positions. The IZA research network is committed to the IZA Guiding Principles of Research Integrity.

The Institute for the Study of Labor (IZA) in Bonn is a local and virtual international research center and a place of communication between science, politics and business. IZA is an independent nonprofit organization supported by Deutsche Post Foundation. The center is associated with the University of Bonn and offers a stimulating research environment through its international network, workshops and conferences, data service, project support, research visits and doctoral program. IZA engages in (i) original and internationally competitive research in all fields of labor economics, (ii) development of policy concepts, and (iii) dissemination of research results and concepts to the interested public.

IZA Discussion Papers often represent preliminary work and are circulated to encourage discussion. Citation of such a paper should account for its provisional character. A revised version may be available directly from the author. 
IZA Discussion Paper No. 9732

February 2016

\section{ABSTRACT \\ The Prodigal Son: Does the Younger Brother Always Care for His Parents in Old Age?}

Studies have shown that the older sibling often chooses to live away from his elderly parents intending to free ride on the care provided by the younger child. In the presented model, we incorporate income effects and depict a different pattern frequently observed in Eastern countries; that is, the older sibling lives near his or her parents and takes care of them in old age. By generalizing the existing model, we show three cases of elderly parents being looked after by (1) the older sibling, (2) the younger sibling, and (3) both siblings, depending on the relative magnitude of the income effect and the strategic incentive for one sibling to free ride on the other. Our study also investigates the effect of changes in relative income on the level of total care received by parents.

JEL Classification: H41, J17

Keywords: location choice, income effect, sibling, elderly care arrangement

Corresponding author:

Mizuki Komura

Institute for Advanced Research

Nagoya University

Furocho Chikusaku

Nagoya 464-8601

Japan

E-mail: komura@soec.nagoya-u.ac.jp 


\section{Introduction}

A certain man had two sons. The younger of them said to his father, "Father, give me my share of your property." $\mathrm{He}$ divided his livelihood between them. Not many days after, the younger son gathered all of this together and traveled into a far country (Luke, 15:11-13).

Taking care of elderly parents has long been an important role in the family institution. Indeed, informal care by adult children is prevalent even in the developed world where social security and the residential care market are well established. According to the OECD (2005), 80\% of informal care is provided by family and friends in the OECD countries, with the care provided by children differing by nation: $24 \%$ in Australia, $28 \%$ in Germany, $48 \%$ in Ireland, $60 \%$ in Japan, $55 \%$ in Korea, $38 \%$ in Spain, $46 \%$ in Sweden, $43 \%$ in the United Kingdom, and $41 \%$ in the United States. Deciding who cares for elderly parents is a major practical issue, especially in case of smaller number of siblings, because then each child has to share a larger part of the financial burden. For instance, according to Agingcare.com estimates, 34 million Americans personally provide care for their older family members, and of these, $34 \%$ spend $\$ 300$ or more of their own money every month and $54 \%$ sacrifice spending money on themselves to take care of their parents. Moreover, the identity of the primary caregiver of elderly parents is of interest from an economic point of view, because caring for parents is a public good as long as the caregivers are altruistic toward their parents. Thus, voluntary caregiving by children will undersupply the care for parents who have a significant free-rider problem.

The primary caregiver of a family differs between Western and Eastern countries. While studies on Western countries show that it is typically the younger son (Konrad et al., 2002; Fontaine et al., 2009), the oldest son more frequently takes on this responsibility in Eastern countries (McLaughlin and Braun, 1998; Liu and Kendig, 2000). To examine this difference, the pioneering work of Konrad et al. (2002) considers the case of private provision of parents' care by two children in a game-theoretic model where the children's location affects the cost of visiting their parents. This study shows that the first-born child uses his first-mover advantage and chooses a location sufficiently far away from his parents and free rides on his altruistic younger brother. ${ }^{2}$ However, they suggest that this finding can change depending on the parents' bequest decisions, as originally proposed by Bernheim et al. (1985). ${ }^{3}$ In this vein, recent studies have theoretically shown that siblings compete for the bequest they expect to receive from parents (Chang and Weisman, 2005; Faith et al., 2008); however, the causality of the strategic bequest motive remains inconclusive (Sloan et al., 1997; Perozek, 1998; Pezzin and Schone, 1999; Sloan et al., 2002; Wakabayashi and Horioka, 2009; Johar et al., 2015). ${ }^{4}$

Unlike the strategic motive mentioned above, this study offers new insight into the caregiving behavior of siblings, focusing on the effect of income gap between two siblings on their location choice and caregiving decisions, which the quasi-linear utility function of Konrad et al. (2002) overlooked. Although location has been shown to affect decisions on caring for parents, the economic circumstances of siblings might also influence their location decisions and thereby their ability to care for their elderly parents. In Konrad

\footnotetext{
${ }^{1}$ At that time, he knew that he was supposed to receive only half of what the older sibling would do (Deuteronomy $21: 17)$.

${ }^{2}$ In a recent article, Maruyama and Johar (2016) quantify Konrad et al.'s model, to find a moderate altruism and cooperation between siblings in the United States. Extending Konrad et al.'s model, Kureishi and Wakabayashi (2010) show that the first-born child tends to live with his parents in return for having received childcare assistance from his parents. Pezzin et al. (2015) also give an interesting example where the distance from parents affects the care arrangement. They present a model in which every child avoids to live with his or her parents since they know that once they decide to live with their parents, they would have to take the entire responsibility of caregiving.

${ }^{3}$ Other possible explanations for caregiving by first-born child include Cox's (1987) exchange model and Chu's (1991) dynasty model.

${ }^{4}$ For an excellent survey on intergenerational transfer from children to parents, see Maruyama and Nakamura (2012).
} 
et al. (2002) model, the older son always uses his position to take up a first-mover advantage. However, the first-mover advantage depends on the income difference between the siblings because the older son cannot free ride on the younger son who has no income to spend on caring for parents. The income gap between siblings affects the first-mover advantage, and hence, the older son may have to serve as primary caregiver. We therefore extend and generalize Konrad et al.'s (2002) model by incorporating the role of income differential between two siblings. Specifically, we consider the income effect because the level of the public good of caregiving depends on not only the marginal cost of caregiving provision (i.e., distance from parents) but also the relative income of the siblings. In particular, income in our model is defined in a broad sense and includes fixed wealth such as land. ${ }^{5}$ Until relatively recently, the eldest son took priority in inheriting the family estate even in developed countries. For instance, until 1947, the eldest son had the right to all family assets in Japan; furthermore, the eldest son was given a special status in Korea under the householder system until implementation of the legal reforms in 2005. Thus, if the siblings recognize a significant income gap between them, it could affect the equilibrium characteristics in their strategic interactions.

After incorporation of the income effect, our generalized model classifies three cases of caregiving: by (i) only the older brother, (ii) only the younger brother, and (iii) both siblings. In particular, we find that the older brother cares for his parents when his income is sufficiently larger than his younger brother's income, concurring with the existing evidence of positive relationship between the elder brother's caregiving and his expected bequest. Our model interprets this relationship as simply an income effect, because the bequest decision can influence the relative sibling income to a large degree.

The remainder of this paper is structured as follows. In section 2, we present the model used. Sections 3 and 4 discuss the results of siblings' location choice and provision of caregiving as a public good. Section 5 discusses the changes in overall care following a change in aggregate income of all siblings. The model is also extended to a cooperative provision of care for parents and fixed location of parents. Section 6 concludes the paper.

\section{Basic Model}

In line with Konrad et al. (2002), we consider the location choice and care provision of adult children who are altruistic toward their elderly parent(s). Our study excludes the gender issue to clarify our contribution and consider the problem of male siblings only. ${ }^{6}$ Consider a family consisting of parents, a first-born child $(i=1)$, and a second-born child $(i=2)$. The utility function of child $i$ is defined as

$$
U_{i}=x_{i}^{\alpha} G^{1-\alpha},
$$

where $x_{i}$ is the private consumption of child $i$ and $G$ is the total amount of care the parents receive from both children. Here, $1-\alpha$ represents the magnitude of altruism: $\alpha=1$ if the child displays no altruistic behavior, and $\alpha=0$ if the child has extremely strong concern about his parents and no interest in private consumption. We thus assume that the care received by parents is the sum of the care provided by both children (overall care hereafter): $G=g_{1}+g_{2}$, where $g_{i}$ is the care provided by child $i$. Following Konrad et al. (2002), we assume that $g_{i}$ denotes the number of visits by child $i$; thus, $G$ is the total number of visits the parents receive.

\footnotetext{
${ }^{5}$ In studies such as Byrne et al. (2009) and Antman (2012), the monetary and opportunity costs of caring time are distinguished by considering formal and informal care.

${ }^{6}$ If we allow for both male and female siblings, our results could change by the additional effects of different productivity in domestic work, including caregiving, or different opportunity cost due to gender wage gap. Some empirical studies explore the children's gender difference effects on care arrangement.
} 
Children and parents choose their place of residence. The location space of the economy is given by $\theta \in[0,1]$. We denote $t_{i}$ and $p$ as the location point of child $i$ and the parents, respectively. Figure 1 shows one of the location patterns for better understanding of the notation.

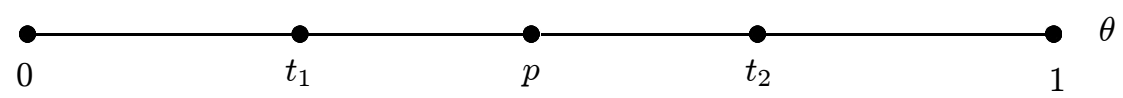

Figure 1. Location space

The budget constraint of child $i$ is given by

$$
y_{i}=x_{i}+\left(1+T_{i}\right) g_{i}
$$

where $y_{i}$ represents income and $T_{i} \equiv\left|t_{i}-p\right|$ denotes the spatial distance of child $i$ 's location from the parents. In (2), $1+T_{i}$ denotes the marginal cost of visit by child $i$ for caring the parents. Following Konrad et al. (2002), we here assume that it consists of two components; (i) a unit contribution of $g_{i}$ eats up his endowment by one unit and (ii) the transportation cost is incurred in the contribution. The former is constant for all children regardless of their location, but the latter depends on the distance between child's and parents' location. Our model reduces to the standard model of privately provided public goods when $T_{i}=0$ for all $i$, but it is not necessarily so since the parents and children choose their location strategically. While $y_{i}$ is an exogenous variable, $t_{i}$ is chosen by each child: $T_{i}=\left|t_{i}-p\right|=0$ if he decides to live with his parents, and $T_{i}=\left|t_{i}-p\right|=1$ when he chooses to live as far away from his parents as possible. Here, $y_{i}$ does not depend on the location, which can be justified by assuming that the labor market is fully integrated and therefore wage income does not depend on the location. To focus on the outcome when the two children differ in timing of their decision as well as in their income, we rule out any gender-related differences between the children.

Following a standard sequential-move decision-making, the timings of the game are as follows:

1. Child 1 chooses location $t_{1}$,

2. Child 2 chooses location $t_{2}$,

3. The parents choose location $p$,

4. Both children decide on their level of care $\left(g_{1}, g_{2}\right)$ simultaneously.

The outcome of this game can be obtained as a sub-game perfect Nash equilibrium. Thus, we apply backward induction and solve the problem from the final stage.

From (1) and (2) and the premise of interior solution, the reaction function in stage four of the game can be obtained as follows:

$$
g_{i}=\frac{(1-\alpha) y_{i}}{1+T_{i}}-\alpha g_{j}, \quad i \neq j
$$

To clarify our main message, we simply assume that $\alpha=1 / 2$ in the following analysis. We also assume that $y_{1}=y$ and $y_{2}=\beta y$ to capture the income gap between the siblings by parameter $\beta \geq 0$, meaning that child 1's income is higher than child 2's income if $\beta<1$, and vice versa if $\beta>1$. 


\section{Equilibrium}

Since the model contains corner solutions, we derive the equilibrium by classifying the outcomes into three cases: (i) both children care for their parents, $g_{1}>0, g_{2}>0$; (ii) child 1 cares for his parents while child 2 free rides, $g_{1}>0, g_{2}=0$; and (iii) child 2 cares for his parents while child 1 free rides, $g_{1}=0, g_{2}>0$.

\subsection{Both children care for their parents}

We first analyze case (i). From (3) for $i=1,2$, the conditions leading to case (i)'s equilibrium are given as follows:

$$
\frac{1+T_{2}}{2\left(1+T_{1}\right)}<\beta<\frac{2\left(1+T_{2}\right)}{1+T_{1}}
$$

Stage 4. If (4) holds, child $i$ chooses the level of $g_{i}$ as follows:

$$
g_{1}=\frac{2\left(1+T_{2}\right)-\beta\left(1+T_{1}\right)}{3\left(1+T_{1}\right)\left(1+T_{2}\right)} y \text { and } g_{2}=\frac{2 \beta\left(1+T_{1}\right)-\left(1+T_{2}\right)}{3\left(1+T_{1}\right)\left(1+T_{2}\right)} y
$$

From (5), we have

$$
g_{1} \frac{\geq}{<} g_{2} \leftrightarrow \frac{1+T_{2}}{1+T_{1}} \geq \beta,
$$

implying that the smaller the distance from the parents and higher his income, the more likely it is for the child to provide a higher level of care. From (5), the total care provided by both children is

$$
G=\frac{\left(1+T_{1}\right) \beta+\left(1+T_{2}\right)}{3\left(1+T_{2}\right)\left(1+T_{1}\right)} y
$$

Stage 3. Parents seek to maximize the total care they receive from their children. The maximization of (6) with respect to $p \in\left[t_{1}, t_{2}\right]$ gives $^{7}$

$$
\begin{aligned}
\frac{\partial G}{\partial p} & =-\frac{y_{2}\left(T_{1}+1\right)^{2} T_{2 p}+y_{1}\left(T_{2}+1\right)^{2} T_{1 p}}{3\left(T_{1}+1\right)^{2}\left(T_{2}+1\right)^{2}}, \\
\frac{\partial^{2} G}{\partial p^{2}} & =\frac{2}{3} \frac{y_{1}\left(T_{2}+1\right)^{3}+y_{2}\left(T_{1}+1\right)^{3}}{\left(T_{1}+1\right)^{3}\left(T_{2}+1\right)^{3}}>0
\end{aligned}
$$

where $T_{i p}=\partial T_{i} / \partial p$. These equations suggest that parents choose either $p=t_{1}$ or $p=t_{2}$. To find the location of parents, we use (6) and compare the total care the parents receive from their children when $p=t_{1}$ and $p=t_{2}$ :

$$
G\left(p=t_{1}\right)-G_{2}\left(p=t_{2}\right)=\frac{y(1-\beta)\left|t_{2}-t_{1}\right|}{3\left(1+\left|t_{2}-t_{1}\right|\right)}
$$

suggesting that the parents live with the son having higher income:

\footnotetext{
${ }^{7}$ We exclude $p>t_{i}>t_{k}$ and $p<t_{i}<t_{k}(i, k=1,2)$, which are inconsistent with the utility maximization by parents.
} 


$$
\begin{array}{ll}
p=t_{1} & \text { if } \beta<1 \\
p=t_{1} \text { or } t_{2} & \text { if } \beta=1 \\
p=t_{2} & \text { if } \beta>1
\end{array}
$$

The parents' choice of location is quite natural because they expect the son with higher income to provide better care.

Stage 2. The younger son (child 2) chooses his location to maximize his utility. Since the parents' location, given by (7), depends on the relative income of the siblings, we investigate the location choice of children as follows:

(a) When child 1's income is higher than child 2's income $(\beta<1)$.

From (7), $p=t_{1}$. Defining $\tau_{2} \equiv\left|t_{2}-t_{1}\right|$, the budget constraint of child 2 can be given by $y_{2}=$ $x_{2}+\left(1+\tau_{2}\right) g_{2}$, where $g_{2}=\left[2 \beta-\left(1+\tau_{2}\right)\right] y / 3\left(1+\tau_{2}\right)$. By substituting this equation into (1), we have the utility of child 2 in the second stage as follows:

$$
U_{2}=\frac{\left(1+\beta+\tau_{2} \beta\right)^{2}}{9\left(1+\tau_{2}\right)} y^{2} .
$$

From the maximization of $U_{2}$, given $t_{1}$, we have

$$
\frac{\partial U_{2}}{\partial \tau_{2}}=\frac{\tau_{2}\left(\tau_{2}+2\right)(1+\beta)(1-\beta)}{9\left(\tau_{2}+1\right)^{2}} y^{2}>0,
$$

Since $\beta<1$, (8) implies that child 2 lives as far away from his brother as possible. Depending on $t_{1}$, child 2 chooses either $t_{2}=0$ or $t_{2}=1$.

To find the location of child 2 , we need to derive the utility of child 2 when he lives at the corner point:

$$
U_{2}\left(t_{2}=0\right)=\frac{\left(1+t_{1}+\beta\right)^{2}}{9\left(1+t_{1}\right)} y^{2} \text { and } U_{2}\left(t_{2}=1\right)=\frac{\left(2-t_{1}+\beta\right)^{2}}{9\left(1+\left(1-t_{1}\right)\right)} y^{2}
$$

giving

$$
U_{2}\left(t_{2}=0\right)-U_{2}\left(t_{2}=1\right)=\frac{\left(2 t_{1}-1\right)}{9} \frac{\left(t_{1}+1\right)\left(2-t_{1}\right)-\beta^{2}}{\left(t_{1}+1\right)\left(2-t_{1}\right)} y^{2} .
$$

Since $\beta<1$ and $t_{1} \in[0,1],\left(t_{1}+1\right)\left(2-t_{1}\right)-\beta^{2}>0$. Thus, from (9), the response function of child 2 is

$$
\begin{aligned}
& t_{2}=0 \quad \text { if } t_{1}>0.5, \\
& t_{2}=0 \text { or } 1 \text { if } t_{1}=0.5, \\
& t_{2}=1 \quad \text { if } t_{1}<0.5 .
\end{aligned}
$$

(b) When child 2's income is higher than child 1's income $(\beta>1)$.

In this case, as shown in (7), $p=t_{2}$; thus, the budget constraint of child 2 is $y_{2}=x_{2}+g_{2}$, where $g_{2}=\left[2 \beta\left(1+\tau_{2}\right)-1\right] y / 3\left(1+\tau_{2}\right)$. As in case (a), the utility function of child 2 becomes 


$$
U_{2}=\frac{\left(1+\left(\tau_{2}+1\right) \beta\right)^{2}}{9\left(\tau_{2}+1\right)^{2}} y^{2}
$$

Again, from the maximization of $U_{2}$, given $t_{1}$, we have

$$
\frac{\partial U_{2}}{\partial \tau_{2}}=-\frac{2 y^{2}\left(1+\left(\tau_{2}+1\right) \beta\right)}{9\left(\tau_{2}+1\right)^{3}}<0 .
$$

Thus, child 2 chooses $t_{2}$ to satisfy $\tau_{2}=\left|t_{2}-t_{1}\right|=0$, implying that he lives as close to his brother as possible:

$$
t_{2}=t_{1}
$$

Stage 1. From (10) and (11), Child 1's location choice in the first stage affects child 2's location choice in the second stage. Child 1 knows that his location would influence child 2's location choice and thus strategically chooses his location before his younger brother makes his choice.

(a) When child 1's income is higher than child 2's income $(\beta<1)$.

By inserting (2), (5), and (7) into (1), we have the objective function of child 1 in the first stage as follows:

$$
U_{1}=\frac{\left(y_{1}+y_{2}+\left|t_{2}-t_{1}\right| y_{1}\right)^{2}}{9\left(\left|t_{2}-t_{1}\right|+1\right)^{2}}
$$

where $t_{2}$ in this equation is given by (10). The first-order conditions for the maximization problem are thus obtained from

$$
\frac{\partial U_{1}\left(t_{2}=0\right)}{\partial t_{1}}=-\frac{2 y_{2}\left(y_{1}+y_{2}+t_{1} y_{1}\right)}{9\left(t_{1}+1\right)^{3}}<0 \text { and } \frac{\partial U_{1}\left(t_{2}=1\right)}{\partial t_{1}}=\frac{2 y_{2}\left(y_{2}+\left(2-t_{1}\right) y_{1}\right)}{9\left(2-t_{1}\right)^{3}}>0 .
$$

Thus, in any case, child 1 minimizes $\left|t_{2}-t_{1}\right|$. The reason why child 1 minimizes his distance from child 2 is simple. Child 1 expects his parents to live with him and wants to make child 2 participate in caregiving. To enable child 2 care for the parents, child 1 tries to live as near to him as possible. However, child 1 cannot reside with child 2 because child 2 would always move away from child 1 to avoid the burden of caring for their parents. Given the reaction of child 2, represented by (10), a possible equilibrium is child 1 choosing $t_{1}=0.5$, minimizing $\left|t_{2}-t_{1}\right|$. That is, child 1 chooses to live at 0.5 to minimize the distance from child 2 and expects the second-born child to adjust by living away in the second stage. In this case, child 2 is indifferent between choosing $t_{1}=0$ and $t_{1}=1$, and, once he chooses either $t_{1}=0$ or $t_{1}=1$, he has no incentive to move.

Summarizing the results, we have the following proposition.

Proposition 1. Suppose that child 1's income is higher than child 2's income $(\beta<1)$. Then, the parent lives with child 1 at $p=t_{1}=0.5$, while child 2 lives at either of the end points $t_{2}=0$ or $t_{2}=1$.

From the information of equilibrium location pattern in (5) and (6), we have the following corollary: 
Corollary 1. Suppose that 1's income is higher than child 2's income $(\beta<1)$. Then, $g_{1}=2(3-\beta) y / 9$, $g_{2}=(4 \beta-3) y / 9, g_{1}-g_{2}=(3-2 \beta) y>0$, and $G=(3+2 \beta) y / 9$.

From (4), the equilibrium characterized by Proposition 1 and Corollary 1 holds if $0<\beta<3 / 4$, by which $g_{1}>0$ and $g_{2}>0$ hold.

(b) When child 2's income is higher than child 1's income $(\beta>1)$.

From (11), we obtain child 1's utility in the first stage as follows:

$$
U_{1}=\frac{1}{9}\left(y_{1}+y_{2}\right)^{2},
$$

implying that child 1's location is not uniquely determined. With (7) and (11), this directly leads to the following proposition.

Proposition 2. Suppose that child 2's income is higher than child 1's income $(\beta>1)$. Then, the parent and the two children live together somewhere (denoted by $\overline{t_{1}}$ ) in the unit space $p=t_{2}=t_{1}=\overline{t_{1}}$.

From the information of equilibrium location in (5) and (6), we have the following corollary:

Corollary 2. Suppose that child 1's income is higher than child 2's income $(\beta>1)$. Then, $g_{1}=$ $(2-\beta) y / 3, g_{2}=(2 \beta-1) y / 3, g_{1}-g_{2}=1-\beta<0$, and $G=(1+\beta) y / 3$.

From (4), the equilibrium characterized by Proposition 2 and Corollary 2 holds if $1<\beta<2$, by which $g_{1}>0$ and $g_{2}>0$ hold.

From Proposition 2, everyone chooses the same location and the second-born child becomes the primary caregiver. In the range $(1<\beta<2)$, a small income gap leads to an interior solution such that both sons are involved in the care of their parents. Since the second-born child has higher income, he provides more care. The parents live at the same location of the second-born child to increase the care received from the primary caregiver. Since the second-born child knows this, he tries to live at the same location of the first-born child to make his brother participate more in caregiving. The first-born child is then indifferent to his location because he knows that his younger brother, the primary caregiver, would follow his choice.

\subsection{Corner solutions}

In the previous subsection, we restricted our analysis to the case of interior solution in which both children care for their parents. We now study the equilibrium pattern when $3 / 4<\beta<2$ does not hold. In this case, only one child cares for his parents and the other free rides on his brother.

(a) When child 1's income is sufficiently higher than child 2's income $(\beta<3 / 4)$.

We first consider the case of $\beta<3 / 4$. Here, child 2 does not have sufficient income to care for his parents; thus, child 1 cares for his parents and child 2 free rides, $g_{1}>0$, and $g_{2}=0$. In the fourth stage, the care provided by each child is, respectively,

$$
g_{1}=G=\frac{y}{2\left(1+\left|p-t_{1}\right|\right)} \text { and } g_{2}=0 .
$$

In the third stage, the parents maximize $G=0.5 y /\left(1+\left|p-t_{1}\right|\right)$ with respect to $p$, with the result that they live with child $1, p=t_{1}$. In the second stage, child 2 accounts for $p=t_{1}$. From this equation, 
the utility of child 2 is $U_{2}=\beta y^{2} / 2$, which does not depend on $t_{2}$, suggesting that the location of child 2 is indeterminate. We here denote $\overline{t_{2}}$ as child 2's location. Finally, in the first stage, child 1 chooses his location to maximize his utility, $U_{1}=y^{2} / 4$; this is so because $p=t_{1}$ and $t_{2}=\overline{t_{2}}$. Since the utility of child 1 is independent of $t_{1}$, the location of child 1 is indeterminate. We express child 1 's location as $\overline{t_{1}}$. In this case, we have $g_{1}=y / 2>g_{2}=0$.

(b) When child 2's income is sufficiently higher than child 1's income $(\beta>2)$.

We next consider the case where child 2 cares for his parents and child 1 free rides; this happens when $\beta>2$. In the fourth stage, given $g_{1}=0$, child 2 chooses $g_{2}$ so as to maximize his utility; thus, we have

$$
g_{2}=G=\frac{\beta y}{2\left(1+\left|t_{2}-p\right|\right)} .
$$

In the third stage, the parents maximize (13) with respect to $p$, implying that the parents live with child $2, p=t_{2}$. Child 2 accounts for $p=t_{2}$ in the second stage, and his utility is given by $U_{2}=\beta^{2} y^{2} / 4$; this does not depend on $t_{2}$, suggesting that the location of child 2 is indeterminate. We thus obtain $\overline{t_{2}}$ as child 2's location. Finally, in the first stage, with $p=t_{2}$ and $t_{2}=\overline{t_{2}}$, child 1 chooses his location to maximize his utility, $U_{1}=\beta y^{2} / 2$. Since $U_{1}$ is independent of $t_{1}$, child 1's location is indeterminate. We express child 1's location as $\overline{t_{1}}$.

Summarizing the location pattern in case of corner solutions, we have the following proposition.

Proposition 3. (i) When child 1's income is sufficiently higher than child 2's income $(\beta<3 / 4)$, the parents and child 1 live together somewhere in the unit space denoted by $\overline{t_{1}} \in[0,1], p=t_{1}=\overline{t_{1}}$, and child 2 is the sole occupant of $\overline{t_{2}} \in[0,1]$.

(ii) When child 2's income is sufficiently higher than child 1's income $(\beta>2)$, the parents and child 2 live together somewhere in the unit space denoted by $\overline{t_{2}} \in[0,1], p=t_{2}=\overline{t_{2}}$, and child 1 is the sole occupant of $\overline{t_{1}} \in[0,1]$.

Corollary 3. (i) When $\beta<3 / 4, g_{1}=y / 2=G$ and $g_{2}=0$; (ii) When $\beta>2, g_{1}=0$ and $g_{2}=\beta y / 2=G$.

Figure 2 summarizes the results.

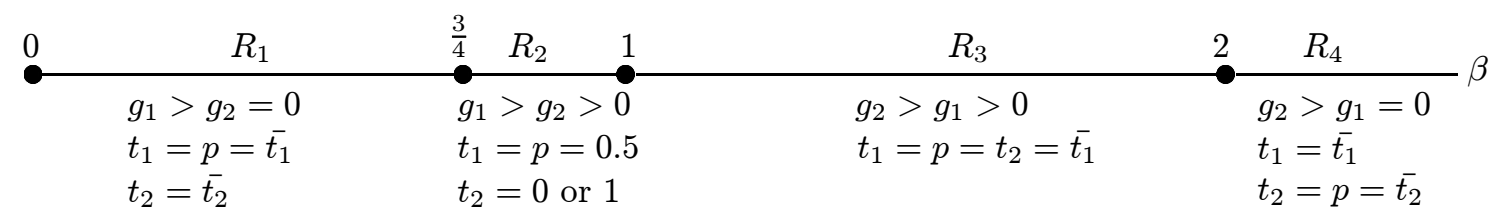

Figure 2. Equilibrium pattern

Note. $\overline{t_{1}}$ and $\overline{t_{2}}$ take arbitrary values in the unit space.

In range $1\left(R_{1}\right)$, the parents live with the elder son and only he takes care of them; both sons are indifferent to their location. The mechanism of this result is interpreted as follows: since the first-born child has more income and the income gap is sufficiently large, he takes the whole responsibility of taking care of his parents. Knowing that only the first-born child takes care of them, the parents choose the same location as the first-born child to receive care from him. For the second-born child, the location choice does not matter since the large income gap enables him to avoid the duty of caregiving. For the 
first-born child, since his location choice does not affect his younger brother's caregiving behavior and because his parents follow him, he too is indifferent to the location choice.

Range $4\left(R_{4}\right)$ applies to the opposite case of the corner solution result in range 1: the parents live with the second-born child and only he takes care of them; both sons are indifferent to their location choice. In this situation, only the rich younger son provides care for their parents, and in order to reduce the cost from distance to the larger caregiving son's provision, the parents choose to live in the same location of the second-born child. Knowing well that his elder brother will not take care of their parents and that they will follow him, the second-born child becomes indifferent to his location choice. Moreover, the first-born child too is indifferent because it does not affect the behavior of his parents and his younger brother's provision.

\section{Discussion}

\subsection{Comparative statics}

In this section, we consider how a change in the relative income of child 1 and child 2 influences overall care, $G$. For this analysis, we consider a change in $\beta$, that is, a change in the aggregate income of both children, keeping child 1's income constant.

We now redefine four regimes according to the level of $\beta$, namely, Regime $1(\beta<3 / 4)$, Regime 2 $(3 / 4<\beta<1)$, Regime $3(1<\beta<2)$, and Regime $4(2<\beta)$. The care provided, $G^{j}$, in each regime $(j=1,2,3,4)$ is given by $G^{1}=y / 2, G^{2}=(3+2 \beta) y / 9, G^{3}=(1+\beta) y / 3$, and $G^{4}=\beta y / 2$, respectively. These outcomes clearly show that an increase in $\beta$ leads to a rise in $G^{j}$ except for Regime 1 . This argument is summarized in Figure 3.

To interpret the effects of an increase in child 2's income on the total contribution, consider first Regime 1 where the income of child 2 is sufficiently small. When $\beta<3 / 4$, the income of child 2 is so small that he does not take care of his parents, $g_{2}=0$, and free rides on the care provided by child 1 . In this case, child 1 lives with his parents, $p=t_{1}$, and chooses $g_{1}=y / 2$. In this context, an increase in child 2's income, represented by an increase in $\beta$, changes neither the location pattern nor contribution level. Once $\beta$ exceeds $3 / 4$, however, child 2 takes care of his parents. Aware of child 2's incentives to take care of his parents, child 1 chooses $t_{1}$ in the first stage so that child 2 becomes more involved in the care of their parents. However, child 2 benefits from second-mover advantage and lives away from his parents and brother. Although an increase in child 2's income allows him to provide a positive amount of care, it reduces the contribution of child 1: An increase in $g_{2}$ allows child 1 to free ride on child 2's contribution and reduces his contribution. The positive effects of an increase in child 2's income on child 2's contribution outweighs the negative (substitution) effects on child 1's contribution, and thus the total amount of private contribution increases.

Once $\beta$ exceeds 1, an increase in child 2's income increases the contribution through three channels, ultimately leading to discontinuity at $\beta=1$. First, an increase in child 2's income increases the contribution of child 2 through the income effect channel. Second, once $\beta$ exceeds 1 , the parents change their location and decide to live with child 2 , reducing the contribution of child 1 , and therefore child 2 increases his contribution. Third, although child 1 tries to live away from his parents as well as child 2 in the first stage, child 2 follows child 1 and decides to live together so as to make child 1 take the burden of care, and thereby increases the care provided by child 1 .

Finally, when $\beta$ exceeds 2 , child 1 free rides on child 2's contribution by choosing $g_{1}=0$. This leads child 2 to live with his parents, thereby reducing the cost of care. The reduction in cost enables child 2 to contribute more for the care of his parents, and thus the total amount of care increases. 


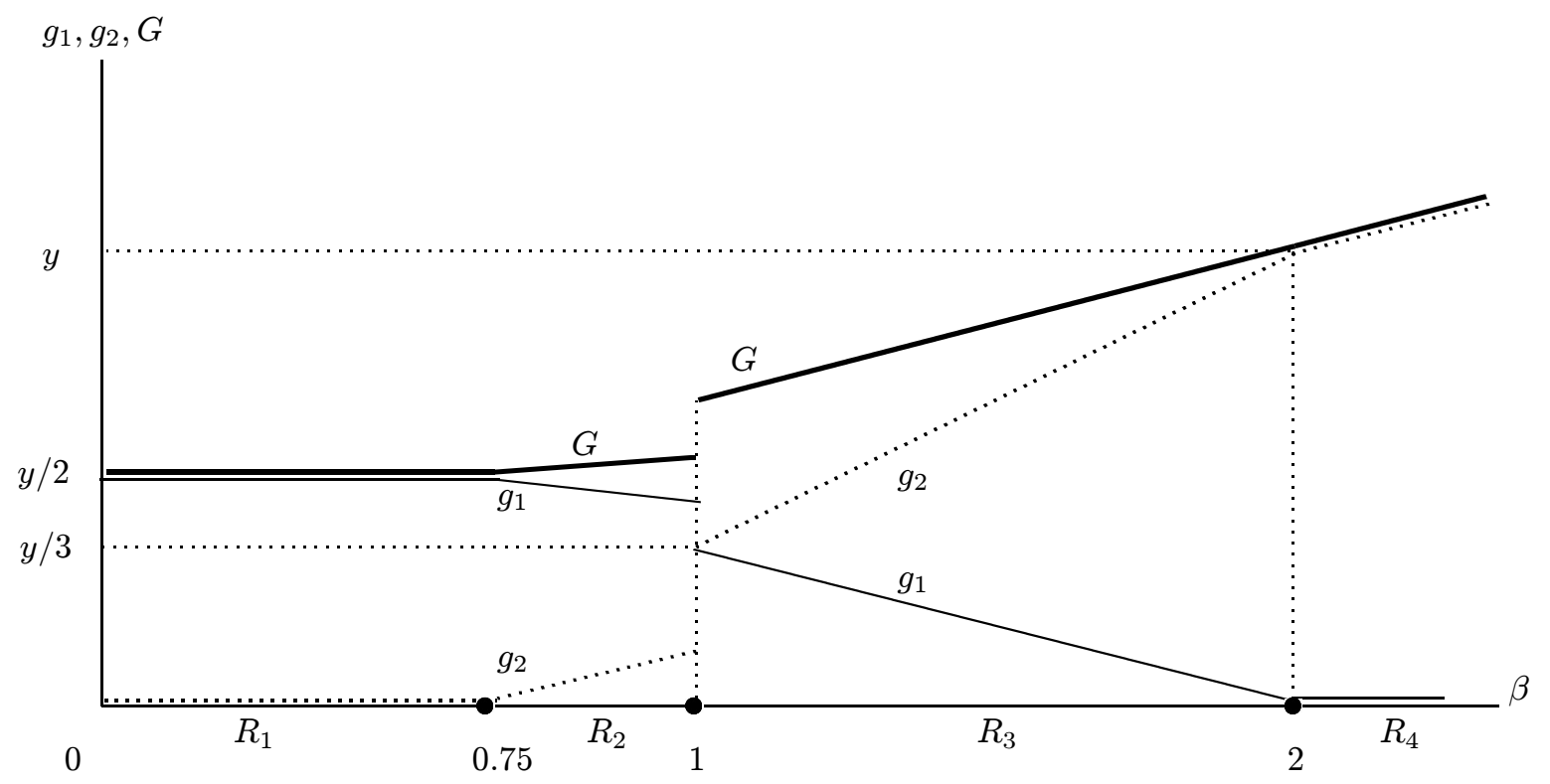

Figure 3. Total care provided by both children

\subsection{Cooperation in provision of care}

In this section, we analyze how the location pattern changes when the model is extended to incorporate cooperative behavior. ${ }^{8}$ We derive the equilibrium when children cooperate in the fourth stage. Since the provision of care for parents has the property of public goods, the total amount of care for parents tends to be inefficiently low. This creates the scope for cooperation between siblings to care for parents.

Assume that, given the location pattern determined in the first, second, and third stages, the siblings cooperate to maximize their joint utilities when caring for their parents. The objective function in the first stage is, thus, given by $U_{1}+U_{2}$. The maximization gives the following condition:

$$
\begin{aligned}
& g_{1}=\frac{(1+\beta) y}{2\left(T_{1}+1\right)} \text { and } g_{2}=0 \text { if } T_{2}>T_{1}, \\
& g_{2}=\frac{(1+\beta) y}{2\left(T_{2}+1\right)} \text { and } g_{1}=0 \text { if } T_{2}<T_{1},
\end{aligned}
$$

where $T_{1} \equiv\left|p-t_{1}\right|$ and $T_{2} \equiv\left|t_{2}-p\right|$.

The parents anticipate these outcomes in the third stage and choose their location; they choose to live with child $1\left(p=t_{1}\right.$ and therefore $\left.T_{1}=0\right)$ if $T_{2}>T_{1}$ and with child $2\left(p=t_{2}\right.$ and therefore $\left.T_{2}=0\right)$ if $T_{2}<T_{1}$. In the second stage, the utility of child 2 is given by $U_{2}=\beta(1+\beta) y^{2} / 2$ when $T_{2}>T_{1}$ and $U_{2}=(\beta-1)(1+\beta) y^{2} / 4$ when $T_{2}<T_{1}$. In both cases, $U_{2}$ does not depend on $t_{2}$, and the location of child 2 in the second stage is not uniquely determined. In this case, the utility of child 1 in the first stage is given by $U_{1}=(1+\beta) y^{2} / 2$, indicating that the location choice does not change the utility, and $t_{1}$ is not determined.

The total amount of care provided jointly to parents is given by $G^{c}=(1+\beta) y / 2>G^{j}(j=1,2,3,4)$, implying that cooperation between siblings increases the amount of care given to parents. This analysis reveals a slight change in location pattern. When the siblings do not cooperate in providing care, we have

\footnotetext{
${ }^{8}$ Reiner and Sielder (2009) also present an insightful model where the siblings negotiate at the fourth stage of care provision and their choice of employment and location affect their bargaining power.
} 
four equilibrium patterns: see Figures 2 and 3 for regimes $1-4$. However, when the siblings cooperate, only one child provides care and regimes 2 and 3 disappear.

\subsection{When parents do not migrate}

So far, we assumed that parents freely migrate after their children choose their location. This setting is plausible if the cost for parents' location change is sufficiently small. However, it could also be difficult for the parents to migrate because of the high migration cost attributable to age-related illnesses or attachment to home. In this section, we examine how the care provision and location choice change when the parents do not migrate. Since the analysis is based on the model already presented in section 3 , we present a brief description of the model here.

The timing of the game is now given as follows: In the first stage, child 1 chooses location $t_{1}$; in the second stage, child 2 chooses location $t_{2}$; and in the final stage, both children decide on their levels of care $\left(g_{1}, g_{2}\right)$ simultaneously.

Since no changes are needed in the final-stage outcome, (4)-(6) hold. Without any loss of generality, we assume that the parents locate at $p=0$, indicating that $t_{i}$ directly represents the distance of child $i$ from the parents.

In the second stage, child 2 maximizes his utility, given by

$$
U_{2}=\frac{\left(1+t_{2}\right)+\left(1+t_{1}\right) \beta}{3\left(1+t_{1}\right) \sqrt{1+t_{2}}} y .
$$

The first- and second-order conditions are respectively given as follows:

$$
\begin{aligned}
\frac{\partial U_{2}}{\partial t_{2}} & =\frac{\left(1+t_{2}\right)-\left(1+t_{1}\right) \beta}{6\left(1+t_{1}\right)\left(\sqrt{1+t_{2}}\right)^{3}} y, \\
\frac{\partial^{2} U_{2}}{\partial t_{2}^{2}} & =\frac{y}{4\left(\sqrt{1+t_{2}}\right)^{5}}\left(\beta-\frac{1+t_{2}}{3\left(1+t_{1}\right)}\right)>0 .
\end{aligned}
$$

The sign of (14) is ambiguous because the marginal benefit and marginal cost of living away from parents work in opposite directions. If child 2 lives away from his parents, he leaves to his older brother the responsibility to provide more caregiving, which thus increases the cost of caregiving. The last inequality in (15) comes from (4), which shows that the location choice of child 2 becomes the corner solution at either $t_{2}=0$ or $t_{1}=1$. Specifically, his choice is determined by the following equation:

$$
U_{2}\left(t_{2}=1\right)-U_{2}\left(t_{2}=0\right)=\frac{y(2-\sqrt{2})}{6}\left(\frac{\sqrt{2}}{1+t_{1}}-\beta\right) .
$$

From (16), we have the reaction function of child 2 as follows:

$$
\begin{array}{ll}
t_{2}=0 & \text { if } \beta>\frac{\sqrt{2}}{1+t_{1}}, \\
t_{2}=0 \text { or } 1 \text { if } \beta=\frac{\sqrt{2}}{1+t_{1}}, \\
t_{2}=1 \quad \text { if } \beta<\frac{\sqrt{2}}{1+t_{1}} .
\end{array}
$$

Equations (17)-(19) show that the location choice of child 1 in the first stage affects the location choice of child 2 in the second stage. Child 1 recognizes its influence on child 2's location choice and hence strategically chooses where to live before his younger brother does. 
To examine the location choice of child 1 , first, assume that child 1 chooses $t_{i}$ to satisfy $\beta>\sqrt{2} /\left(1+t_{1}\right)$. This choice forces child 2 to live with his parents; that is, $t_{2}=0$. In this case, (4) is limited to

$$
\frac{\sqrt{2}}{1+t_{1}}<\beta<\frac{2}{1+t_{1}} .
$$

When (20) is satisfied, the care provided by each child can be given respectively by

$$
g_{1}=\frac{2-\beta\left(1+t_{1}\right)}{3\left(1+t_{1}\right)} y \text { and } g_{2}=\frac{2 \beta\left(1+t_{1}\right)-1}{3\left(1+t_{1}\right)} y .
$$

To derive the location of child 1 in the first stage, we insert (21) into the utility function of child 1 . The objective function of child 1 in the first stage then becomes

$$
U_{1}=\frac{1+\left(1+t_{1}\right) \beta}{3 \sqrt{1+t_{1}}} y .
$$

The first- and second-order conditions for the maximization problem are thus obtained, respectively, by

$$
\begin{aligned}
\frac{\partial U_{1}}{\partial t_{1}} & =\frac{\left(1+t_{1}\right) \beta-1}{6\left(\sqrt{1+t_{1}}\right)^{3}} y, \\
\frac{\partial^{2} U_{1}}{\partial t_{1}^{2}} & =\frac{3-\left(1+t_{1}\right) \beta}{12\left(\sqrt{1+t_{1}}\right)^{5}} y>0 .
\end{aligned}
$$

The last inequality in (23) comes from (20), indicating that the location choice of child 1 becomes the corner solution at either $t_{1}=0$ or $t_{1}=1$. To determine child 1 's choice, we check the sign of

$$
U_{1}\left(t_{1}=1\right)-U_{1}\left(t_{1}=0\right)=\frac{y(2-\sqrt{2})}{3 \sqrt{2}}\left(\beta-\frac{\sqrt{2}}{2}\right) .
$$

We find that

$$
\begin{array}{ll}
t_{1}=1 & \text { if } \beta>\frac{\sqrt{2}}{2}, \\
t_{1}= & 0 \text { or } 1 \text { if } \beta=\frac{\sqrt{2}}{2}, \\
t_{1}=0 & 0 \quad \text { if } \beta<\frac{\sqrt{2}}{2} .
\end{array}
$$

Since (17) and (24) can hold at the same time, $t_{1}=1$ and $t_{1}=0$ can be an equilibrium. In this case, from (20), $\sqrt{2} / 2<\beta<1$ ensures that both children care for their parents. In contrast, (17) and (24) do not hold at the same time, and hence, $t_{1}=0$ and $t_{2}=0$ do not hold at equilibrium.

We can similarly derive the equilibrium location when (19) holds, and hence the equilibrium can be summarized as follows. ${ }^{9}$ :

Proposition 4. Suppose that the parents do not migrate. (i) If $\sqrt{2} / 2<\beta<1$, then $t_{1}=1$ and $t_{2}=0$. In this case, the care provided by each child is given by $g_{1}=(1-\beta) y / 3$ and $g_{2}=(4 \beta-1) y / 6$, respectively; (ii) If $1<\beta<\sqrt{2}$, then $t_{1}=0$ and $t_{2}=1$. In this case, the care provided by each child is given by $g_{1}=(4-\beta) y / 6$ and $g_{2}=(\beta-1) y / 3$, respectively.

\footnotetext{
${ }^{9}$ For the proof, see Komura and Ogawa (2015).
} 
We now address the equilibrium pattern when $\sqrt{2} / 2<\beta<\sqrt{2}$ does not hold. Here, only one child cares for his parents and the other free rides. First, consider the case of $\beta<\sqrt{2} / 2$. Here, child 2 does not have sufficient income to care for his parents, and hence, child 1 cares for his parents and child 2 free rides, $g_{1}>0$, and $g_{2}=0$. The care provided by each child is, respectively, $g_{1}=0.5 y /\left(1+t_{1}\right)$ and $g_{2}=0$. Substituting these equations into the utility function of child 2, we have $U_{2}=0.5 \beta y^{2} /\left(1+t_{1}\right)$. Because the utility of child 2 does not depend on his location, he is indifferent to choosing his location, implying that child 1 cannot choose his location in the first stage to control the location of child 2 determined in the second stage. We denote the location choice of child 2 as $\overline{t_{2}} \in[0,1]$. In this case, the utility of child 1 in the first stage is given by $U_{1}=0.25 y^{2} /\left(1+t_{1}\right)$. Thus, child 1 chooses $t_{1}=0$ to maximize his utility.

When $\sqrt{2}<\beta$, the equilibrium location can be obtained in a similar manner. In this case, the income of child 1 is so small that he cannot care for his parents, and hence, child 2 cares for his parents while child 1 free rides, $g_{1}=0$, and $g_{2}>0$.

The equilibrium can be summarized as follows:

Proposition 5. Suppose that the parents do not migrate. (i) If $\beta<\sqrt{2} / 2$, then $t_{1}=0$ and $t_{2}=\overline{t_{2}}$. In this case, the care provided by each child is $g_{1}=\beta y / 2$ and $g_{2}=0$, respectively; (ii) If $\sqrt{2}<\beta$, then $t_{1}=\overline{t_{1}}$ and $t_{2}=0$. In this case, the care provided by each child is $g_{1}=0$ and $g_{2}=\beta y / 2$, respectively.

When $\beta<\sqrt{2} / 2$, child 2 has no preference on his location since he does not provide care to his parents. Child 1 cannot use his location to induce child 2 to choose a location he prefers. In addition, child 1 cares for his parents, and hence, he chooses to live with them to minimize the caregiving cost. A similar argument applies when $\beta>\sqrt{2}$.

The equilibrium pattern when parents do not migrate is depicted in Figure 4. When the income differential between the two siblings is large enough to satisfy $\beta<\sqrt{2} / 2$ or $\beta \geq \sqrt{2}$ and one of the two cares for their parents and the other free rides, then child 1 cannot use his location as a strategic variable to control the location of his younger brother. In this case, the child who has the larger income lives with his parents and takes care of them while the other free rides.

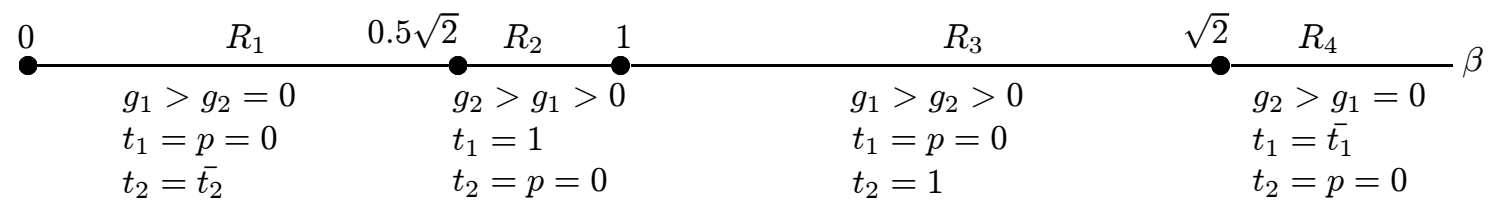

Figure 4. Equilibrium pattern when the parents do not migrate

Note. $\overline{t_{1}}$ and $\overline{t_{2}}$ take arbitrary values in the unit space.

When the income differential between the two siblings is sufficiently small to lead both children care for their parents, child 1 uses his location choice to induce his younger brother to choose the location he desires. If child 1's income is larger than child 2's income, that is, $\beta<1$, he realizes that his younger brother provides less care for his parents. To make him provide more care, child 1 moves to live far away from the parents, thus caring less for his parents. This action induces the younger brother to take more care of their parents, since the brothers are in a situation of strategic substitution in terms of caregiving. Since the younger brother cares for their parents more, he lives with them. A similar argument explains the location pattern when $\beta>1$, in which case child 1 lives with his parents. 


\section{Conclusion}

In this study, we investigated the location choice and parents' care arrangements of two siblings considering their income differential. Specifically, we formulated a model wherein their caregiving decisions are influenced by their relative incomes as well as their distance from parents (i.e., the marginal caregiving cost), in line with Konrad et al. (2002)'s approach. We use this generalized model of income effects and examine two cases of care arrangements, given the income differential. First, when the income gap is sufficiently small, both children take part in caregiving. In this case, a strategic incentive exists to live far away from parents. This decision is taken because relative distance is a determinant of the care each child needs to provide and the older child can utilize his first-mover advantage (this case essentially corresponds to the result presented by Konrad et al. (2002)). Second, when the income differential is sufficiently large, the child earning more (either the older or younger child) takes the responsibility of caring for his parents irrespective of the other's location choice. This novel result makes a unique contribution to the body of knowledge on this topic; it partially explains the different care arrangements seen in Western and Eastern countries.

The possibility of the elder son taking care of his parents that this analysis found be partially supported by evidence from Japan. According to the National Institute of Population (1988), the first-born child tends to live with his/her parents in Japan. In case the parents have more than two children and they live with one of the children who married in the period 1955-1959, the ratio that the first-born son lived with his parents was $61.3 \%$, whereas the ratio for other children was $32.9 \%$. Although the ratio of the extended family declined over time, the tendency for parents to live with their first-born child has not changed. ${ }^{10}$ In this sort of situation, the National Family Research of Japan (2003) observed the birth order effect that the elder child receives higher education on average. ${ }^{11}$ We note this tendency from the case of two children born during the period 1956-1965, as an example. According to the data, the ratio of both children having the same education level was $54.2 \%$, that of the elder child enjoying higher education level than the younger was $26.2 \%$, and that of the opposite case was $19.5 \%$. This trend of the elder child having higher education lasted up to the next cohort born in 1966-1975, showing that the ratio that the elder (younger) received higher education than the other was 26.7\% (19.9\%); for the cohort of 1976-85, this was $26.9 \%(21.3 \%)$. Studies have also explored the relationship between birth order and education level after controlling for the number of children in the household; many of them found that elder male children tend to receive higher education (Tomabechi, 2012). From the existing literature that showed a positive relationship between education and income, we can expect that the first-born child (son) enjoys higher income than the others, and, as stated, the first-born child tends to be the primary care giver in Japan.

Before concluding this study, some limitations need to be mentioned. First, we analyzed the behavior of siblings treating income as exogenous. However, future works should aim to endogenize income by including former decisions such as on educational and location choice. Second, distinguishing income into labor and non-labor income may enable a rich description of adult children's decisions, taking account of the price effect of the opportunity cost of caregiving, as in Byrne et al. (2009) and Antman (2012). Third, we specify the utility function to obtain analytical results. It is not surprising that our qualitative results hold in an appropriate range of preference parameters, but the results might be affected quantitatively if children have extreme preferences. Finally, considering the vast literature on care arrangements, future

\footnotetext{
${ }^{10}$ For instance, the ratio for the first-born son who married during the period $1985-1987$ was $35.3 \%$ and that for others remained $23.0 \%$. In the case of single child, the ratio that the child who married during 1955-1959 lived with his/her parents was $45.0 \%$, which has consistently declined to $25.0 \%$ in $1985-1987$.

${ }^{11}$ National Family Research of Japan (2003) is a report on a large research survey held by Japan Society of Family Sociology in 2004. This targeted the Japanese citizens living in Japan and born in 1926-1975, the period often used in analysis to understand Japanese families.
} 
studies could introduce a new concept of cross-effect of incomes into the empirical analysis. Although some studies have investigated how one's educational level influences others' decisions on the caregiving for elderly parents (Fontaine et al., 2009), few authors have considered income itself as the element of cross-effect. If we consider the income effect as one possible scenario, it would be interesting to test our model to compare the customs prevalent in Western and Eastern countries.

\section{Acknowledgements}

This study is conducted as part of the project "A Socioeconomic Analysis of Households in Environments Characterized by Aging Population and Low Birth Rates", undertaken at Research Institute of Economy, Trade and Industry (RIETI). The authors are grateful to Shinichiro Iwata, Keisuke Kawata, Kazutoshi Miyazawa, Sayaka Nakamura, Takashi Unayama, and all participants of the conferences and seminars at Nagoya Univ., Sun Yat-Sen Univ., Seoul National Univ., Freiburg Univ., Hiroshima Univ., Meijo Univ., RIETI, ARSC, Housing Research \& Advancement Foundation of Japan, and the North American meetings of the RSAI for their constructive comments and suggestions. The research has also been supported by grants from the JSPS (nos.25245042 and 15K17074) and Kampo Foundation.

\section{References}

Antman, F. M. (2012). Elderly care and intrafamily resource allocation when children migrate. Journal of Human Resources, 47(2), 331-363.

Bernheim, B. D., Shleifer, A., \& Summers, L. H. (1985). The strategic bequest motive. Journal of Political Economy, 93(6), 1045-1076.

Byrne, D., Goeree, M. S., Hiedemann, B., \& Stern, S. (2009). Formal home health care, informal care, and family decision making. International Economic Review, 50(4), 1205-1242.

Chang, Y. M., \& Weisman, D. L. (2005). Sibling rivalry and strategic parental transfers. Southern Economic Journal, 71(4), 821-836.

Chu, C. C. (1991). Primogeniture. Journal of Political Economy 99(1), 78-99.

Cox, D. (1987). Motives for private income transfers. Journal of Political Economy, 95(3), 508-546.

Faith, R. L., Goff, B. L., \& Tollison, R. D. (2008). Bequests, sibling rivalry, and rent seeking. Public Choice, 136(3-4), 397-409.

Fontaine, R., Gramain, A., \& Wittwer, J. (2009). Providing care for an elderly parent: interactions among siblings?. Health Economics, 18(9), 1011-1029.

Komura, M., \& Ogawa, H. (2015), The prodigal son: Does the younger brother always care for his parents in old age?. RIETI Discussion Paper Series 15-E-062.

Konrad, K. A., Kunemund, H., Lommerud, K. E., \& Robledo, J. R. (2002). Geography of the family. American Economic Review, 92(4), 981-998.

Kureishi, W., \& Wakabayashi, M. (2010). Why do first-born children live together with parents? Japan and the World Economy, 22(3), 159-172.

Johar, M., Maruyama, S., \& Nakamura, S. (2015). Reciprocity in the formation of intergenerational coresidence. Journal of Family and Economic Issues, 36(2), 192-209. 
Liu, W. T., \& Kendig, H. (2000). Critical issues of caregiving: east-west dialogue. (eds) Liu, W. T., \& Kendig, H., Who should care for the elderly? World Scientific Publishing Co.

Maruyama, S., \& Nakamura, S. (2012). Intergenerational transfers from children to parents: a critical review, Economic Review (Keizai Kenkyu), 63(4), 318-332.

Maruyama, S., \& Johar, M. (2016). Do siblings free-ride in 'being there' for parents?. Quantitative Economics, forthcoming.

McLaughlin, L. A., \& Braun, K. L. (1998). Asian and Pacific Islander cultural values: considerations for health care decision making. Health \& Social Work, 23(2), 116-126.

National Institute of Population (1988), 9th Survey on Procreativity, Tokyo.

OECD (2005). Long-Term Care for Older People, OECD, Paris.

Perozek, M. G. (1998). A reexamination of the strategic bequest motive. Journal of Political Economy, $106(2), 423-445$.

Pezzin, L. E. \& Schone, B. S. (1999), Intergenerational household formation, female labor supply and informal caregiving: a bargaining approach. Journal of Human Resources, 34(3), 475-503.

Pezzin, L. E., Pollak, R. A., \& Schone, B. S. (2015). Bargaining power and intergenerational coresidence. Journals of Gerontology: Series B, 70(6), 969-80.

Rainer, H. \& Siedler, T (2009), O brother, where art thou? The effects of having a sibling on geographic mobility and labour market outcomes. Economica, 76(303), 528-556.

Sloan, F. A., Picone, G., \& Hoerger, T.J. (1997). The supply of children's time to disabled elderly parents. Economic Inquiry, 35(2), 295-308.

Sloan, F. A., Zhang, H. H., \& Wang, J. (2002). Upstream intergenerational transfers. Southern Economic Journal, 69(2), 363-380.

Tomabechi, N. (2012), How family characteristics and sibship composition affect educational attainment? Annual Reports of the Tohoku Sociological Society 41(1), 103-114.

Wakabayashi, M., \& Horioka, C. Y. (2009). Is the eldest son different? The residential choice of siblings in Japan. Japan and the World Economy, 21(4), 337-348. 